\title{
Caecal Adenocarcinoma in a Patient Mimicking Complicated Appendicitis
}

\begin{abstract}
Muhammad Azhar, ${ }^{*}$ Tayyaba Batool
Department of Paediatric Surgery, National Institute of Child Health, Jinnah Sindh Medical University, Karachi

ABSTRACT

Colorectal cancer (CRC) presenting with intestinal obstruction is uncommon in paediatric age and carries poor prognosis. We report a case of a 13-year-old boy who presented with acute intestinal obstruction, clinically appearing to be secondary to complicated appendicitis. Exploratory laparotomy revealed a caecal mass which was resected. Histopathology report showed only inflammatory cells with no sign of malignancy. The patient was discharged home after smooth recovery but re-admitted after 2 months with recurrence of intestinal obstruction. Considering clinical behavior of the patient, the tissue blocks obtained from first surgery were reviewed and it turned out to be a poorly differentiated adenocarcinoma with positive mesenteric lymph nodes for metastatic carcinoma..
\end{abstract}

Key words: Colorectal cancer; Intestinal obstruction; Missed diagnosis; Appendicitis

Correspondence*: Muhammad Azhar, Department Paediatric Surgery, National Institute of Child Health (NICH), Jinnah Sindh Medical University Rafique Shaheed Road, Karachi, Pakistan

E-mail: azhar_khawaja@hotmail.com @ (2018, Azhar et al.

Submitted: 13-09-2017

Accepted: 05-11-2017

Conflict of Interest: None

Source of Support: Nil

This is an open-access article distributed under the terms of the Creative Commons Attribution License, which permits unrestricted use, distribution, and reproduction in any medium, provided the original work is properly cited.

\section{INTRODUCTION}

Colorectal cancer is a rare malignancy in children and adolescents.[1] The estimated annual incidence is one case per million.[2] Due to rarity it is seldom suspected in children. Moreover unlike adults, the clinical presentation of this malignancy is non-specific and by the time diagnosis is made, disease becomes advanced in stage. Here we report a case of mucinous adenocarcinoma of caecum with short term follow up, highlighting various aspects of its clinical presentation and management issues encountered.

\section{CASE REPORT}

A 13-year boy presented to emergency department with 7 days history of right iliac fossa pain and fever, followed by abdominal distension, bilious vomiting, and absolute constipation. There was no past history and family history of gastrointestinal problems. Examination revealed abdominal distension with marked tenderness in lower abdomen and vague lump was palpable in right iliac fossa. Digital rectal examination was unremarkable. X-ray abdomen showed distended gut loops with air-fluid levels. Laboratory investigations were within normal range, except raised white cells count.

Provisional diagnosis was intestinal obstruction due to complications of acute appendicitis. After adequate resuscitation and optimization, exploratory laparotomy was performed. Per-operatively a circumferential mass was found in caecum about $2.5 \times 2.1 \mathrm{~cm}$ (Fig.1), causing proximal dilatation with collapse of distal large bowel. Limited right hemicolectomy, involving distal $5 \mathrm{~cm}$ of terminal ileum up to proximal one-third of ascending colon, followed by ileocolic anastomosis, was done. Patient was discharged home after recovery and seen in outpatient clinic with biopsy report, which showed 
acute and chronic inflammatory cells, with no signs of malignancy. Patient did not come for follow up as advised.

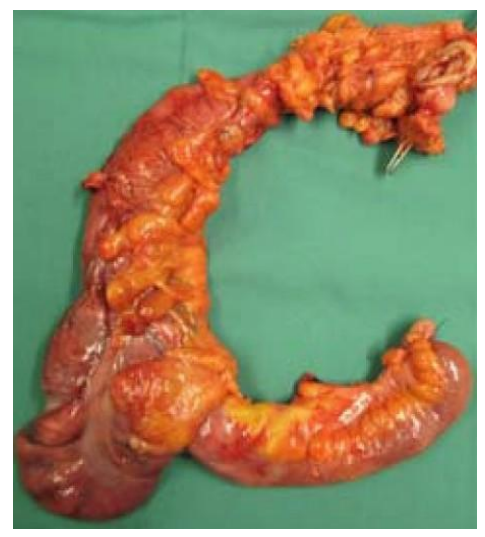

Figure 1: Showing resected part of terminal ileum, caecum and proximal ascending colon. Arrow shows thickened caecum.

Patient was re-admitted after 2 months with symptoms of intestinal obstruction. On clinical examination patient appeared cachexic. On abdominal examination a firm and ill-defined mass was palpable in right iliac fossa. Digital rectal examination was unremarkable. Boy was managed conservatively and nutritionally supported with total parenteral nutrition (TPN). This atypical presentation of patient led us to probe further into the disease. Ultrasound followed by CT scan was done (Fig.2). Tissue blocks obtained from initial surgery were reviewed and it showed poorly differentiated adenocarcinoma with 8 out of 16 lymph nodes having metastatic disease. All resection margins were free of tumor. CT scan Abdomen and chest were done for the metastatic workup suggestive of markedly dilated gut loops with involvement of mesenteric and few celiac lymph nodes. CT chest showed enlarged supra-diaphragmatic lymph nodes bilaterally. No evidence of metastatic lesion seen in lungs. CAE levels were normal.Due to advanced stage of disease palliative chemotherapy was started by oncologist. Patient's condition defoliated further following first dose of chemotherapy and died.

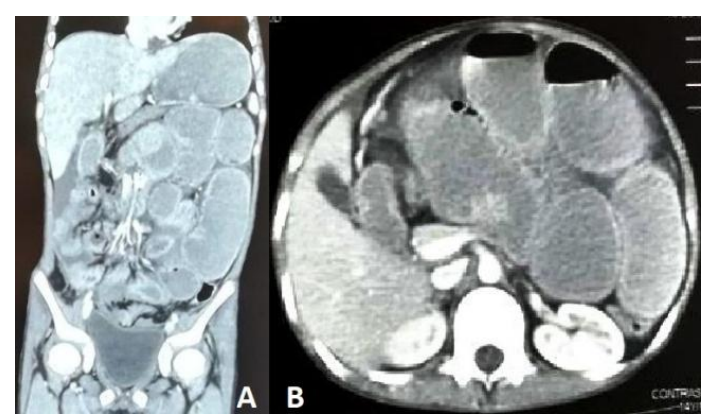

Figure 2 (A, B): CT scan images (2 months post operative) shows loaded and dilated gut loops

\section{DISCUSSION}

Although colorectal carcinoma (CRC) is among the most common malignancies in patients over 40-years of age, it is rare in younger population.[3] The disease is usually sporadic,[4] but about 10-30\% have some predisposing factors,[5] which include familial adenomatous polyposis (FAP), ulcerative colitis, Crohn's disease, and PeutzJegher syndrome.[6] Despite being very infrequent, it is known to be the most common solid malignancy of gastrointestinal tract in childhood.[5] The overall prognosis is poor because of delay in diagnosis, advanced stage at presentation and poor histological differentiation.[7]

The presentation of patients with CRC is nonspecific and can be similar to those of many benign gastrointestinal conditions in children.[5] Commonly seen symptoms are abdominal pain and vomiting,[8] but change in bowel habits, weight loss and anemia have been reported.[5] Presentation mimicking acute appendicitis has also been reported [9]; similarly a working diagnosis of complicated appendicitis was our initial impression.

Colorectal cancer can involve any part of large bowel but most commonly observed sites are rectum followed by transverse colon. $[7,10]$ Tumors involving the caecum and descending colon usually become bulky before the child is symptomatic.[9] In our case, tumor was found arising from caecum. The most common histological type of colorectal cancers in large bowel is mucinous adenocarcinoma, which was also observed in our patient, and it bears poor prognosis. Overall five year survival rate is $7 \%$ to $12 \%$.[10]

The diagnosis of colorectal carcinoma is based on a high index of suspicion which can be confirmed by sigmoidoscopy or colonoscopy and tissue biopsy. Contrast studies, ultrasonography and computed tomography are required to assess the extent of the disease.[9] We were unable to perform these radiologic investigations because our patient was operated in emergency and full assessment of the extension of the disease was only possible at the time of laparotomy.

Surgery is the mainstay of the treatment for colorectal cancers. The goal is complete resection of tumor with clear margins and associated lymph nodes, followed by primary anastomosis. Chemotherapy and radiotherapy are used as adjunct modes for the control of local and distant metastasis and recurrence. When the tumor is non-resectable with local metastasis beyond lymph nodes, incisional biopsy with neoadjuvant chemotherapy 
is advised. In patients with intestinal obstruction and non-resectable tumor, permanent colostomy is preferred as a palliative procedure. In cases where tumor is resectable but doubt exists about tumor margins, segmental excision with temporary stoma are advisable followed by chemotherapy.[10]

Our case was unique as its diagnosis was missed earlier and presented 2 months later with intestinal obstruction. Further evaluation paved the way to diagnosis of this rare malignancy in paediatric age which in fact, was metastatic at initial presentation. Although our patient had a significant history of abdominal distension and absolute constipation but at the same time his initial symptoms mimicked complicated appendicitis. Therefore, one must have strong suspicion of this rare entity even in children. Similarly if histopathology results do not match with clinical behavior of the patient and operative findings, it is wise to review and verify the results again.

Consent: Authors have submitted signed consent form from legal guardian of the patient and available with editorial office.

Authors' Contribution: All authors were involved in manuscript writing, literature review, and final approval of the manuscript.

\section{REFERENCES}

1. Sultan I, Rodriguez-Galindo C, El-Taani H, Pastore G, Casanova M, Gallino G, et al. Distinct features of colorectal cancer in children and adolescents. Cancer. 2010; 116:758-65.

2. Pappo AS, Furman WL. Management of infrequent cancers in childhood. In: Pizzo PA, Poplack DC, eds. Principles and Practice of Pediatric Oncology. 5th ed. Philadelphia: Lippincott Williams \& Wilkins; 2006:1172-1200.

3. Zaidi A, Badar F, Ahmed Q, Yousaf A, Shujaat A. Colorectal carcinoma in children-experience at a tertiary care cancer centre in Pakistan. Asian Pacific J Cancer Prevention. 2009; 10:789-92.

4. Blumer SL, Anupindi SA, Adamson PC, Lin H, Price AP, Markowitz RI, et al. Sporadic adenocarcinoma of the colon in children: case series and review of the literature. J Pediatr Hematol Oncol. 2012; 34:e137-e141.

5. Koh KJ, Lin LH, Huang SH, Wong JU. CARE-pediatric coIon adenocarcinoma: a case report and literature review comparing differences in clinical features between children and adult patients. Medicine. 2015; 94:e503

6. Singer G, Hoellwarth ME. Colorectal carcinomas in children: an institutional experience. Pediatr Surg Int. 2012; 28:591-5.

7. Karnak I, Ciftci AO, Senocak ME, BykpamukÅu N. Colorectal carcinoma in children. J Pediatr Surg. 1999; 34:1499504.

8. Salas-Valverde S, Lizano A, Gamboa Y, Vega S, Barrantes $\mathrm{M}$, Santamaría S, et al. Colon carcinoma in children and adolescents: prognostic factors and outcome-a review of 11 cases. Pediatr Surg Int. 2009; 25:1073-6.

9. Al-Tonbary Y, Darwish A, El-Hussein A, Fouda A. Adenocarcinoma of the colon in children: case series and minireview of the literature. Hematol Oncol Stem Cell Therapy. 2013; 6:29-33.

10. Zamir N, Ahmed S, Akhtar J. Mucinous adenocarcinoma of colon. APSP J Case Rep. 2010; 1:20. 